\title{
Review of: "Ten-year longitudinal investigation of astigmatism: The Yamagata Study (Funagata)"
}

\author{
Atsushi Kawahara
}

Potential competing interests: The author(s) declared that no potential competing interests exist.

This paper is a longitudinal study of the relationship between astigmatism and age, and deals with agerelated changes in astigmatism in the same individuals. It is interesting and easy to understand. The authors must be congratulated for this well conducted research.

The authors performed vector analysis for astigmatism using the Alpins method. They stated that the findings were that (1) the magnitude of corneal astigmatism does not increase with age, but the magnitude of refractive astigmatism does, (2) astigmatic shift to against-the-rule astigmatism is seen from the $40 \mathrm{~s}$ to the $60 \mathrm{~s}$, and (3) astigmatic shift to against-the-rule astigmatism does not accelerate with age. However, since there have been several similar reports, albeit cross-sectional studies, it's hard to be said that this paper has contributed to the latest findings. The following additional analyses should be performed.

1. The characteristics of corneal and refractive astigmatism differ between men and women [1-3]. However, since astigmatism changes with age, as shown in this study, gender differences in agerelated changes in astigmatism in patients should be investigated. A previous study [4] may be helpful.

2. In this study, the polar values are treated as the primary endpoint. This paper states that the refractive axis changes with age, but it is insufficient to evaluate only by the change in the polar values. A mathematical and statistical analysis using torque [5] within the Alpins method should also be performed. A previous study [6] will also be helpful for this.

3. Since analysis techniques based on the polar values are suitable for dealing with the effects of steepening and flattening of astigmatic changes near the 0,90 , and 180 degree polar axes, when analyzing astigmatism away from these polar axes (especially oblique astigmatism), this technique has limitations [5]. Therefore, I would like to propose an analysis using the X-Y coordinate analysis [7] (or the power vector analysis [8]). That's because oblique astigmatism is still an issue, especially for refractive correction with toric intraocular lenses [9-11].

\section{References}

1. Relationships between preoperative astigmatism and corneal optical power, axial length, intraocular pressure, gender, and patient age. Ninn-Pedersen K. J Refract Surg. 1996 May-Jun;12(4):472-82.

2. Gender- and age-related differences in corneal topography. Goto T, Klyce SD, Zheng X, Maeda N, Kuroda T, Ide C. Cornea. 2001 Apr;20(3):270-6. 
3. Refractive, corneal and ocular residual astigmatism: distribution in a German population and agedependency - the Gutenberg health study. Schuster AK, Pfeiffer N, Schulz A, Hoehn R, Ponto KA, Wild PS, Blettner M, Beutel ME, Lackner KJ, Münzel T, Mirshahi A. Graefes Arch Clin Exp Ophthalmol. 2017 Dec;255(12):2493-2501.

4. Sex-related differences in corneal astigmatism and shape with age. Hayashi K, Sato T, Sasaki H, Hirata A, Yoshimura K. J Cataract Refract Surg. 2018 Sep;44(9):1130-1139.

5. Vector analysis of astigmatism changes by flattening, steepening, and torque. Alpins NA. J Cataract Refract Surg. 1997 Dec;23(10):1503-14

6. Astigmatic change in biaxial microincisional cataract surgery with enlargement of one incision: a prospective controlled study. Kaufmann C, Thiel MA, Esterman A, Dougherty PJ, Goggin M. Clin Exp Ophthalmol. 2009 Apr;37(3):254-61.

7. Bivariate analysis of surgically induced regular astigmatism. Mathematical analysis and graphical display. Naeser K, Hjortdal JO. Ophthalmic Physiol Opt. 1999 Jan;19(1):50-61.

8. Power vectors: an application of Fourier analysis to the description and statistical analysis of refractive error. Thibos LN, Wheeler W, Horner D. Optom Vis Sci. 1997 Jun;74(6):367-75.

9. Refractive outcome of toric intraocular lens calculation in cases of oblique anterior corneal astigmatism. Sheen Ophir S, LaHood B, Goggin M. J Cataract Refract Surg. 2020 May;46(5):688-693.

10. Influence of posterior corneal astigmatism on the outcomes of toric intraocular lens implantation in eyes with oblique astigmatism. Nakano S, lida M, Hasegawa Y, Hiraoka T, Oshika T. Jpn J Ophthalmol. 2021 Mar;65(2):288-294.

11. Prediction of postoperative refractive astigmatism before toric intraocular lens implantation. Kawahara A. BMC Ophthalmol. 2021 May 8;21(1):202. 